Ibn Al-Haitham Jour. for Pure \& Appl. Sci. 35(1)2022

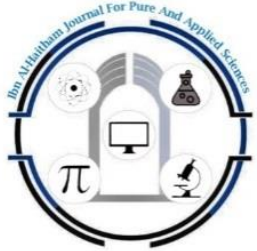

Ibn Al Haitham Journal for Pure and Applied Science

Journal homepage: http://jih.uobaghdad.edu.iq/index.php/j/index

\title{
Strongly Maximal Submodules with A Study of Their Influence on Types of Modules
}

Fatima M. Mohialdeen

Mathematics Department, College of

Education Ibn Al-Haitham for pure Sciences,

University of Baghdad, Iraq

Fatima.mohy.fm@gmail.com

\author{
Buthyna N. Shihab \\ Mathematics Department, College of \\ Education Ibn Al-Haitham for pure science, \\ University of Baghdad, Iraq \\ Dr.buthyna@yahoo.com
}

Article history: Received 24, August, 2021, Accepted 26, September, 2021, Published in January 2022.

Doi: 10.30526/35.1.2802

\section{Abstract}

Let $\mathrm{S}$ be a commutative ring with identity, and $\mathrm{A}$ is an $\mathrm{S}$-module. This paper introduced an important concept, namely strongly maximal submodule. Some properties and many results were proved as well as the behavior of that concept with its localization was studied and shown.

Keywords: Maximal submodule, regular module, regular ring, semi-simple module, prime module.

\section{Introduction}

Along with this paper, $\mathrm{S}$ is a commutative ring with identity, and $\mathrm{A}$ is an S-module. A proper submodule $\mathrm{N}$ of an $\mathrm{S}$-module $\mathrm{A}$ is named maximal if there exists a submodule $\mathrm{D}$ of $\mathrm{A}$ such that $\mathrm{N} \subsetneq \mathrm{D} \subseteq \mathrm{A}$, then $\mathrm{D}=\mathrm{A}[1][11]$. Equivalently, $\mathrm{N}$ is the maximal submodule in $\mathrm{A}$ if and only if $\mathrm{A} / \mathrm{N}$ is a simple S-module [1][12]. Maximal submodules may not exist; for instance, the Z-module $\mathbb{C}$ has no maximal submodules. The main goal of this paper is to introduce a new concept called strongly maximal submodule (for short, SM-submodule) where a proper non-zero submodule B of an S-module A is said to be strongly maximal submodule if and only if, for every non-zero ideal $\mathrm{E}$ of $\mathrm{S}$ implies $\mathrm{A} / \mathrm{E}^{2} \mathrm{~B}$ is a regular module. Field house is defined in [9], a pure submodule of the form: A submodule D of an S-module A is pure if $\mathrm{IA \cap D}=\mathrm{ID}$ for every ideal I of $\mathrm{S}$ and Sahera introduced in [2], the definition of F-regular module, where module A is said to be F-regular if and only if every submodule of A is pure Every strongly maximal submodule is a maximal submodule, but the opposite does not true. This paper is divided into three sections. We reviewed some basic definitions and properties needed in our next work. Section three introduced the definition of strongly maximal submodule. Lots of properties and examples of this concept were shown. In section four, the 
behavior of strongly maximal submodules under localization was some characterized and results were proved.

\section{Basic concepts and Results}

This part includes some well-known definitions, concepts, and results that are useful for us in our study of the next section.

\section{Proposition (2.1)}

Every submodule of the regular module is regular [2].

\section{Proposition (2.2)}

An S-module A is cyclic if and only if it is isomorphic to a factor module of S [4].

\section{Proposition (2.3)}

An S-module $A$ is simple if and only if $A \cong S / E$ for some maximal ideal $\mathrm{E}$ of $\mathrm{S}$ [4] [1].

\section{Definition (2.4)}

A submodule $\mathrm{B}$ of an $\mathrm{S}$-module $\mathrm{A}$ is called prime if $\mathrm{B} \neq \mathrm{A}$, and whenever $\mathrm{tx} \in \mathrm{B}$ for $\mathrm{t} \in \mathrm{S}$ and $\mathrm{x} \in \mathrm{A}$ we have either $\mathrm{t} \in[\mathrm{B}: \mathrm{A}]$ or $\mathrm{x} \in \mathrm{B}[5]$.

\section{Definition (2.5)}

A submodule B of an S-module A is called a semimaximal submodule if and only if $\mathrm{A} / \mathrm{B}$ is a semi-simple S-module [3, definition (2.1.1), $\mathrm{p}_{32}$.

\section{Definition (2.6)}

Let $\mathrm{B}$ be a submodule of an S-module $A$, the closure of $B$ is denoted by $C L(B)=\{x \in A$ : $[\mathrm{B}:(\mathrm{x})]$ essential in $\mathrm{S}\}$. It is clear that $\mathrm{CL}(\mathrm{B})$ is a submodule of A containing $\mathrm{B}$. That is $\mathrm{B} \subseteq$ CL(B) [7] .

\section{S3: Strongly Maximal Submodules with its advantages}

In this section, the concept of strongly maximal submodule (for short, SM-submodule) was introduced, which was a generalization of the concept the strongly maximal ideal in a ring $S$. Several examples and properties were proved also a lot of characterizations, and different results were presented.

Let us start with our basic definition.

\section{Definition (3.1)}

Let $\mathrm{A}$ be an S-module, and B be a non-zero proper submodule of A. Then B is named strongly maximal submodule (for short SM-submodule) if and only if, for every non-zero ideal $\mathrm{E}$ of $\mathrm{S}$ implies $\mathrm{A} / \mathrm{E}^{2} \mathrm{~B}$ is a regular module.

Examples and Remarks (3.2) 


\section{Ibn Al-Haitham Jour. for Pure \& Appl. Sci. 35(1)2022}

1. All the following modules have no SM-submodules.

(i) $\mathrm{Z}$ as a Z-module.

(ii) $Z_{p}$ as a $Z$-module, $p$ is a prime number.

(iii) $\mathrm{Z}_{\mathrm{p}}$ as a $\mathrm{Z}_{\mathrm{p}}$-module, $\mathrm{p}$ is a prime number.

2. Every simple $S$-module has no SM-submodule. But the opposite is not true and the following example shows that: The module $\mathrm{A}=\mathrm{Z}_{4} \oplus \mathrm{Z}$ as a $\mathrm{Z}$-module. Since A has no SMsubmodules, A is not a simple module. Also notice examples (ii) and (iii) in no.(1) .

3. It is important to note that it is not necessary that all modules contain SM-submodules; for example $\mathrm{Zp}^{\infty}$ as- Z-module.

Since, all the submodules of $\mathrm{Zp}^{\infty}$ are of the form $\left\langle 1 / \mathrm{p}^{\mathrm{i}}+\mathrm{Z}\right\rangle$, where $\mathrm{p}$ is a prime number and $\mathrm{i}=0,1,2 \ldots$

Now, we write $N=\left\langle 1 / \mathrm{p}^{\mathrm{i}}+\mathrm{Z}\right\rangle$ and let $\mathrm{E}$ be an ideal of $\mathrm{Z}$. If we take $\mathrm{E}=\langle 1\rangle$, then, $\mathrm{Zp} \mathrm{p}^{\infty} / \mathrm{E}^{2} \mathrm{~B}$ $=\mathrm{Zp}^{\infty} /\langle 1\rangle^{2} \mathrm{~B}=\mathrm{Z \textrm {p } ^ { \infty }} / \mathrm{B} \cong \mathrm{Zp}^{\infty}$ is not a regular module and hence $\mathrm{B}=\left\langle 1 / \mathrm{p}^{\mathrm{i}}+\mathrm{Z}\right\rangle$ is not SMsubmodule of $\mathrm{Zp}^{\infty}$. That is, $\mathrm{Z} \mathrm{p}^{\infty}$ has no SM-submodules.

Also, we can give another example $\mathrm{Z}_{8}$ as a $\mathrm{Z}_{8}$-module that has no SM-submodules .Since $\left\langle\overline{2}>\right.$ and $\left\langle\overline{4}>\right.$ are not SM- submodules in $\mathrm{Z}_{8}$.

4. The submodule $\left\langle\overline{3}>\right.$ of a $\mathrm{Z}_{6}$-module $\mathrm{Z}_{6}$ is an SM-submodule. To clarify, let $\mathrm{E}$ be an ideal of a ring $\mathrm{Z}_{6}$.

if $\mathrm{E}=\langle\overline{1}\rangle$, then $\mathrm{Z}_{6} /\langle\overline{1}\rangle^{2}\langle\overline{3}\rangle=\mathrm{Z}_{6} /\langle\overline{3}\rangle \cong \mathrm{Z}_{3}$ is a regular module .

if $\mathrm{E}=\langle\overline{2}\rangle$, then $\mathrm{Z}_{6} \mid\langle\overline{2}\rangle^{2}\langle\overline{3}\rangle=\mathrm{Z}_{6} /\langle\overline{0}\rangle \cong \mathrm{Z}_{6}$ is a regular module .

if $\mathrm{E}=\langle\overline{3}\rangle$, then $\mathrm{Z}_{6} /\langle\overline{3}\rangle^{2}\langle\overline{3}\rangle=\mathrm{Z}_{6} /\langle\overline{3}\rangle \cong \mathrm{Z}_{3}$ is a regular module.

Therefore $\left\langle\overline{3}>\right.$ is an SM-submodule of $\mathrm{Z}_{6}$.

In general, all submodules of $\mathrm{Z}_{6}$ as a $\mathrm{Z}_{6}$-module are $\mathrm{SM}$-submodules.

5. In $\mathrm{Z}_{10}$ as a $\mathrm{Z}_{20}$-module, the submodule $\mathrm{B}=\langle\overline{5}\rangle$ is an SM-submodule. Since if we take $\mathrm{E}=$ $\langle\overline{1}\rangle,\langle\overline{2}\rangle,\langle\overline{10}\rangle,\langle\overline{4}\rangle,\langle\overline{5}\rangle$, where $\mathrm{E}$ is ideal of $\mathrm{Z}_{20}$, then $\mathrm{Z}_{20} / \mathrm{E}^{2}\langle\overline{5}\rangle$ is a regular module for all ideal $\mathrm{E}$ of $\mathrm{Z}_{20}$. This ends the proof of example.

6. Consider $\mathrm{Z}_{4}$ as a $\mathrm{Z}$-module. The submodule $\left\langle\overline{2}>\right.$ is not $\mathrm{SM}$-submodule of $\mathrm{Z}_{4}$. Since $\mathrm{Z}_{4} / \mathrm{E}^{2}\langle\overline{2}\rangle$ is not regular, $\mathrm{E}$ is an ideal of $\mathrm{Z}$. To prove that, take $\mathrm{E}=\langle\overline{4}\rangle$. Then, $\mathrm{Z}_{4} /\langle\overline{4}\rangle^{2}\langle\overline{2}\rangle$ $\cong \mathrm{Z}_{4}$ is not regular module.

7. Let $\mathrm{Z}_{4}$ as a $\mathrm{Z}_{4}$-module. Then the submodule $\mathrm{B}=\langle\overline{2}\rangle$ is not an $\mathrm{SM}$-submodule. Notice if $\mathrm{E}$ $=\left\langle\overline{2}>\right.$ then $\mathrm{Z}_{4} / \mathrm{E}^{2}\langle\overline{2}\rangle$ is not regular module. 


\section{Ibn Al-Haitham Jour. for Pure \& Appl. Sci. 35(1)2022}

8. Let $\mathrm{B}=\left\langle\overline{2}>\right.$ be a submodule of a $\mathrm{Z}_{20}$-module $\mathrm{Z}_{10}$. Since $\mathrm{Z}_{10} / \mathrm{E}^{2} \mathrm{~B}=\mathrm{Z}_{10} /\langle\overline{2}\rangle^{2}\langle\overline{2}\rangle \cong \mathrm{Z}_{8}$ is not a regular module, where $\mathrm{E}=\left\langle\overline{2}>\right.$ is an ideal of $\mathrm{Z}_{20}$.

9. Let $\mathrm{A}=\mathrm{Z}_{6} \oplus \mathrm{Z}_{3}$ be an $\mathrm{Z}_{12}$-module and $\mathrm{B}=\langle\overline{2}\rangle \bigoplus\langle\overline{0}\rangle$ be a submodule of $\mathrm{A}$. Then $\mathrm{A} / \mathrm{E}^{2} \mathrm{~B}$ $=\mathrm{Z}_{6} \oplus \mathrm{Z}_{3} / \mathrm{E}^{2}(\langle\overline{2}\rangle \oplus\langle\overline{0}\rangle)$ is regular module where $\mathrm{E}=\langle\overline{1}\rangle,\langle\overline{2}\rangle,\langle\overline{3}\rangle,\langle\overline{4}\rangle$ and $\langle\overline{6}\rangle$ be ideals of $\mathrm{Z}_{12}$. Therefor $\mathrm{B}=\left\langle\overline{2}>\oplus\left\langle\overline{0}>\right.\right.$ is an SM-Submodule of $\mathrm{A}=\mathrm{Z}_{6} \oplus \mathrm{Z}_{3}$.

10. Consider $\mathrm{A}=\mathrm{Z}_{6} \oplus \mathrm{Z}$ as a $\mathrm{Z}$-module. Then the submodule $\mathrm{B}=\langle\overline{3}\rangle \oplus\langle\overline{2}\rangle$ of $\mathrm{A}$ is not $\mathrm{SM}$ submodule. Since $\mathrm{A} / \mathrm{E}^{2} \mathrm{~B}=\mathrm{Z}_{6} \oplus \mathrm{Z} /\langle\overline{2}\rangle^{2}(\langle\overline{3}\rangle \oplus\langle\overline{2}\rangle)=\mathrm{Z}_{6} \oplus \mathrm{Z} /\langle\overline{0}\rangle \bigoplus\langle\overline{8}>$ is not a regular module, where $\mathrm{E}=\langle\overline{2}>$ is an ideal of $\mathrm{Z}$.

11. Every SM-submodule is maximal but the opposite is not true and the following example shows that: The submodule $\left\langle\overline{2}>\right.$ of a $\mathrm{Z}$-module $\mathrm{Z}_{4}$ is a maximal submodule in $\mathrm{Z}_{4}$ but it is not a SM-submodule, see no.(6) .

12. A submodule of an SM-submodule is not necessary to be an SM-submodule, for example: A submodule $\left\langle\overline{2}>\right.$ in a $\mathrm{Z}_{6}$-module $\mathrm{Z}_{6}$ is SM-submodule. See no.(4), While $\langle\overline{0}\rangle$ is a submodule of $\langle\overline{2}>$ and it is not SM-submodule .

13. The intersection of two SM-submodules is not condition to be SM-submodule, for example : The two submodules $\langle\overline{2}\rangle,\left\langle\overline{3}>\right.$ in $\mathrm{Z}_{6}$-module $\mathrm{Z}_{6}$ are SM- Submodules but $\langle\overline{2}>\cap$ $\langle\overline{3}\rangle=\langle\overline{0}\rangle$ is not an SM-submodule

14. More generally, let $\left\{\mathrm{B}_{\mathrm{i}}\right\}_{\mathrm{i}=1}^{\mathrm{n}}$ be a finite collection of SM-submodules of an S-module A. Then $\cap_{i=1}^{n} B_{i}$ is not always SM-submodule.

15. The direct sum of two SM-submodules of an S-module A is not necessary to be an SMsubmodule, for example: Let $\langle\overline{2}\rangle,\langle\overline{3}\rangle$ be two SM-submodules of a $\mathrm{Z}_{6}$-module $\mathrm{Z}_{6}$, but $\left\langle\overline{2}>\oplus\left\langle\overline{3}>=\mathrm{Z}_{6}\right.\right.$ is not an SM-submodule.

16. From the fact that every maximal submodule is a semimaximal by [3, Remarks and Examples (2.1.2), $\mathrm{p}_{32}$ ], and the fact no.(11), we obtain that every SM-submodule of an Smodule $\mathrm{A}$ is a semimaximal while the converse is not true in general and the following shows that: Let $6 Z$ be a submodule of a $Z$-module $Z$. Then, $6 Z$ is a semimaximal submodule of $Z$. Since $6 Z=2 Z \cap 5 Z$ where $2 Z, 5 Z$ are maximal submodules of $Z$. But $6 Z$ is not an SMsubmodule of $Z$. Since $Z /(2 Z)^{2}(6 Z)=Z / 24 Z \cong Z_{24}$ is not a regular module .

\section{Proposition (3.3)}

Let $\mathrm{B}, \mathrm{D}$ be two submodules of an S-module A with $\mathrm{B} \subseteq \mathrm{D}$. Then $\mathrm{B}$ is SM-submodule in $\mathrm{D}$ when B is SM-submodule in A.

\section{Proof:}

Suppose $\mathrm{B}$ is $\mathrm{SM}$-submodule in $\mathrm{A}$, then $\mathrm{A} / \mathrm{E}^{2} \mathrm{~B}$ is regular module for every non-zero ideal $\mathrm{E}$ of $\mathrm{S}$. Since $\mathrm{D} / \mathrm{E}^{2} \mathrm{~B}$ is a submodule of $\mathrm{A} / \mathrm{E}^{2} \mathrm{~B}$ (Notice, $\mathrm{E}^{2} \mathrm{~B} \subseteq \mathrm{B} \subseteq \mathrm{D}$ ), and hence by proposition (2.1), $\mathrm{D} / \mathrm{E}^{2} \mathrm{~B}$ is a regular submodule of $\mathrm{A} / \mathrm{E}^{2} \mathrm{~B}$. Thus $\mathrm{B}$ is SM-submodule in $\mathrm{D}$. 


\section{Ibn Al-Haitham Jour. for Pure \& Appl. Sci. 35(1)2022}

Next, we will give an application to a proposition (3.3)

\section{Corollary (3.4)}

Let $\mathrm{A}$ be an S-module and $\mathrm{B}$ be a proper submodule of $\mathrm{A}$. If $\mathrm{B}$ is an SM-submodule of $\left[\mathrm{B}_{\mathrm{A}} \dot{\mathrm{A}} \mathrm{A}\right]$ and $\left[\mathrm{B}_{\mathrm{A}} \dot{\mathrm{A}} \mathrm{A}\right]$ is an SM-submodule in $\mathrm{A}$, then, $\mathrm{B}$ is an SM-submodule in A.

\section{Proof:}

It clear that $\mathrm{B} \subseteq\left[\mathrm{B}_{\mathrm{A}} \mathrm{A}\right] \subseteq \mathrm{A}$. Therefore, by using proposition (3.3), we conclude that $\mathrm{B}$ is SM-submodule in A.

Now, we will give the sufficient condition for a submodule to not be SM-submodule.

\section{Proposition (3.5)}

Let $\mathrm{A}$ be an $\mathrm{S}$-module. If $\mathrm{A}$ is cyclic module (if $\mathrm{A}=\mathrm{Sx}$ for some $\mathrm{x} \in \mathrm{A}$ ) and $\mathrm{ann}_{\mathrm{s}}(\mathrm{x})$ is maximal ideal of $\mathrm{S}$, then A has no SM-submodule.

\section{Proof:}

Since $A=S x$ for some $x \in A$, then $A$ is isomorphic to a factor module of $S$ by proposition (2.2). We can define $\mathrm{f}: \mathrm{S} \rightarrow \mathrm{A}$ such that $\mathrm{f}(\mathrm{r})=\mathrm{rx}$. It is easily to show that $\mathrm{f}$ is well- define and epimorphisim, by the first fundamental theorem of isomorphism $\mathrm{S} / \mathrm{Ker} \mathrm{f} \cong \mathrm{A}$. Next, Ker $\mathrm{f}=\left\{\mathrm{r} \in \mathrm{S}: \mathrm{f}(\mathrm{r})=0_{\mathrm{A}}\right\}=\left\{\mathrm{r} \in \mathrm{S}: \mathrm{rx}=0_{\mathrm{A}}\right\}=\operatorname{ann}_{\mathrm{s}}(\mathrm{x})$ That is $\mathrm{S} / \operatorname{ann}_{\mathrm{s}}(\mathrm{x}) \cong \mathrm{A}$. Also, we have $\operatorname{ann}_{\mathrm{s}}(\mathrm{x})$ is maximal ideal of $S$ which implies $S / \operatorname{ann}_{\mathrm{s}}(\mathrm{x})$ is simple and hence $\mathrm{A}$ is simple. Therefore, by examples and remarks ((3.2) No. (2)), we get the result.

Next is the application of proposition (3.5)

\section{Corollary (3.6)}

If a non-zero prime and semi-simple S-module A, then A has no SM-submodule.

\section{Proof:}

Suppose that $\mathrm{A}$ is a prime and semi-simple module, then, we obtain $\mathrm{A}$ is simple module. To prove this, assume that $\mathrm{A}$ is not simple which implies $\mathrm{A}$ is a direct sum of simple $\mathrm{S}$ modules. Then, there exists a simple module $\mathrm{M}_{1}$ and $\mathrm{M}_{2}$ which are a direct summand of $\mathrm{A}$ with $M_{1} \neq M_{2} . M_{1} \cong S / E, M_{2} \cong S / D$ where $E$ and $D$ are maximal ideals of $S$, by proposition (2.3). But $A$ is prime module, then $\operatorname{ann}_{\mathrm{s}}\left(\mathrm{M}_{1}\right)=\mathrm{E}=\operatorname{ann}_{\mathrm{s}}(\mathrm{A})$ and $\operatorname{ann}_{\mathrm{s}}\left(\mathrm{M}_{2}\right)=\mathrm{D}=\operatorname{ann}_{\mathrm{s}}(\mathrm{A})$. Thus $\mathrm{E}=\mathrm{D}$ which implies that $\mathrm{M}_{1}=\mathrm{M}_{2}$, and this is a contradiction. Hence, $\mathrm{A}$ is a simple module and by using proposition (3.5), we have A has no SM-submodule.

As a direct of corollary (3.6), we have the following.

\section{Corollary (3.7)}




\section{Ibn Al-Haitham Jour. for Pure \& Appl. Sci. 35(1)2022}

Let $\mathrm{P}$ be a prime and semimaximal submodule of an $\mathrm{S}$-module $\mathrm{A}$. Then the quotient module by $\mathrm{P}$ has no SM-submodule.

\section{Proof:}

Since $\mathrm{P}$ is a semimaximal submodule of $\mathrm{A}$, then by definition (2.5), we have $\mathrm{A} / \mathrm{P}$ is a semisimple S-module. On the other hand, $\mathrm{P}$ is a prime submodule of $\mathrm{A}$, then, by [3, proposition (1.1.51)] we obtain that $\mathrm{A} / \mathrm{P}$ is a prime $\mathrm{S}$-module, and hence by corollary (3.6), then $\mathrm{A} / \mathrm{P}$ is a simple $\mathrm{S}$-module and hence $\mathrm{A} / \mathrm{P}$ has no SM-submodule.

\section{S4: The behavior of SM-submodules under localization.}

Let $\mathrm{K}$ be a subset of a ring $\mathrm{S}, \mathrm{W}$ is multiplication closed if the two condition hold:

1. $I \in W$.

2. $x y \in W$ for every $x, y \in W$.

We know that every proper ideal $\mathrm{E}$ in $\mathrm{S}$ is prime if and only if $\mathrm{S}-\mathrm{E}$ is multiplicatively closed, see [8].If $\mathrm{A}$ is an $\mathrm{S}$-module and $\mathrm{W}$ be a multiplicatively closed on $\mathrm{S}$ such that $\mathrm{W} \neq<0>$ , then $S_{w}$ be the set for all fractional $r / w$ where $r \in S$ and $w \in W$ and $A_{w}$ be the set of all fractional $\mathrm{m} / \mathrm{w}$ where $\mathrm{m} \in \mathrm{A}$ and $\mathrm{w} \in \mathrm{W}$. For $\mathrm{m}_{1}, \mathrm{~m}_{2} \in A$ and $\mathrm{w}_{1}, \mathrm{w}_{2} \in \mathrm{W}, \mathrm{m}_{1} / \mathrm{w}_{1}=\mathrm{m}_{2} / \mathrm{w}_{2}$ if and only if $\exists \mathrm{t} \in \mathrm{W}$ such that $\mathrm{t}\left(\mathrm{w}_{1} \mathrm{~m}_{1}-\mathrm{w}_{2} \mathrm{~m}_{2}\right)=0$. Also, we can make $A_{\mathrm{w}}$ in to $S_{\mathrm{w}}$-module by setting $\mathrm{m}_{1} / \mathrm{w}_{1}+\mathrm{m}_{2} / \mathrm{w}_{2}=\left(\mathrm{w}_{2} \mathrm{~m}_{1}+\mathrm{w}_{1} \mathrm{~m}_{2}\right) / \mathrm{w}_{1} \mathrm{w}_{2}$ and $\left(\mathrm{r} / \mathrm{w}_{1}\right)\left(\mathrm{m}_{1} / \mathrm{w}_{2}\right)=\mathrm{rm}_{1} / \mathrm{w}_{1} \mathrm{w}_{2}$ for every $\mathrm{m}_{1}, \mathrm{~m}_{2}$ $\in A$ and every $r \in S, w_{1}, w_{2} \in W$. If $W=S-E$ where $E$ is a prime ideal, we used $A_{E}$ instead of $A_{\mathrm{w}}$ and $S_{E}$ instead of $S_{w}$. If a ring has only one maximal ideal, then it is called a local ring. Hence $S_{E}$ is often called the localization of $S$ at $E$, similar $A_{E}$ is the $r / 1, \forall r \in S$ and $\boldsymbol{\Phi}: A$ $\rightarrow \mathrm{A}_{\mathrm{w}}$ such that $\boldsymbol{\Phi}(\mathrm{m})=\mathrm{m} / 1, \forall \mathrm{m} \in \mathrm{A}$. Furthermore, if B is a submodule of an S-module A and $\mathrm{W}$ be a multiplicatively closed in $S$, then $B_{w}=\{n / w: n \in B, w \in W\}$ be a submodule on $S_{w^{-}}$ module, see [8].

In this section we study the behavior of an SM-submodule under localization and several of results have been proved.

The following lemma is needed in our next result.

\section{Lemma (4.1) [10]}

Let $\mathrm{A}$ be an $\mathrm{S}$-module and $\mathrm{B}, \mathrm{L}$ are two submodules of $\mathrm{A}$. Then, $\mathrm{B}=\mathrm{L}$ if and only if $\mathrm{B}_{\mathrm{P}}=\mathrm{L}_{\mathrm{P}}$ for every maximal ideal $\mathrm{P}$ of $\mathrm{S}$.

The following proposition study the relationship between a module A and its locally and prove that they are equivalent.

\section{Proposition (4.2):}

Let $\mathrm{A}$ be an S-module and $\mathrm{B}$ is nonzero proper submodule of $\mathrm{A}$. Then, $\mathrm{B}_{\mathrm{P}}$ is $\mathrm{SM}$ submodule of an $\mathrm{S}_{\mathrm{P}}$-submodule $\mathrm{A}_{\mathrm{P}}$ if and only if B is SM-submodule of an S-module A.

\section{Proof:}


Suppose that $\mathrm{B}$ is nonzero proper submodule of $\mathrm{A}$. We must prove that $\mathrm{A} / \mathrm{E}^{2} \mathrm{~B}$ is a regular $\mathrm{S}$-module for every nonzero ideal $\mathrm{E}$ of $\mathrm{S}$; that is, every submodule of $\mathrm{A} / \mathrm{E}^{2} \mathrm{~B}$ is pure. Let $\mathrm{L} / \mathrm{E}^{2} \mathrm{~B}$ be a submodule of $\mathrm{A} / \mathrm{E}^{2} \mathrm{~B}$. It is clear that $\mathrm{I}\left(\mathrm{L} / \mathrm{E}^{2} \mathrm{~B}\right) \supseteq \mathrm{I}\left(\mathrm{A} / \mathrm{E}^{2} \mathrm{~B}\right) \cap\left(\mathrm{L} / \mathrm{E}^{2} \mathrm{~B}\right)$ where $\mathrm{I}$ is an ideal of $S$. Now, to prove $\mathrm{I}\left(\mathrm{L} / \mathrm{E}^{2} \mathrm{~B}\right) \subseteq \mathrm{I}\left(\mathrm{A} / \mathrm{E}^{2} \mathrm{~B}\right) \cap\left(\mathrm{L} / \mathrm{E}^{2} \mathrm{~B}\right)$. Let $\mathrm{x} \in \mathrm{I}\left(\mathrm{L} / \mathrm{E}^{2} \mathrm{~B}\right)$. Then $\mathrm{x}=$ $\sum_{\mathrm{i}=1}^{\mathrm{n}} \mathrm{a}_{\mathrm{i}}\left(\mathrm{l}_{\mathrm{i}}+\mathrm{E}^{2} \mathrm{~B}\right)$. Therefore $\mathrm{xs} / \mathrm{s}=\left(\sum_{\mathrm{i}=1}^{\mathrm{n}} \mathrm{a}_{\mathrm{i}}\left(\mathrm{l}_{\mathrm{i}}+\mathrm{E}^{2} \mathrm{~B}\right)\right) \mathrm{s} / \mathrm{s} \in \mathrm{I}_{\mathrm{P}}\left(\mathrm{L}_{\mathrm{P}} / \mathrm{E}_{\mathrm{P}}^{2} \mathrm{~B}_{\mathrm{P}}\right)$ but $\mathrm{L}_{\mathrm{P}}$ is $\mathrm{SM}$-submodule in $A_{P}$, then $I_{P}\left(L_{P} / E_{P}^{2} B_{P}\right)=\left(I_{P}\left(A_{P} / E_{P}^{2} B_{P}\right)\right) \cap\left(L_{P} / E_{P}^{2} B_{P}\right)$ which implies $x s / s \quad \epsilon$ $\mathrm{I}_{\mathrm{P}}\left(\mathrm{A}_{\mathrm{P}} / \mathrm{E}_{\mathrm{P}}^{2} \mathrm{~B}_{\mathrm{P}}\right) \cap\left(\mathrm{L}_{\mathrm{P}} / \mathrm{E}_{\mathrm{P}}^{2} \mathrm{~B}_{\mathrm{P}}\right) \quad=\quad\left(\left(\mathrm{I}_{\mathrm{P}} \mathrm{A}_{\mathrm{P}}+\mathrm{E}_{\mathrm{P}}^{2} \mathrm{~B}_{\mathrm{P}}\right) / \mathrm{E}_{\mathrm{P}}^{2} \mathrm{~B}_{\mathrm{P}}\right) \cap\left(\mathrm{L}_{\mathrm{P}} / \mathrm{E}_{\mathrm{P}}^{2} \mathrm{~B}_{\mathrm{P}}\right.$ )$=\left(\left((\mathrm{IA})_{\mathrm{P}}+\left(\mathrm{E}^{2} \mathrm{~B}\right)_{\mathrm{P}}\right) /\left(\mathrm{E}^{2} \mathrm{~B}\right)_{\mathrm{P}}\right) \cap\left(\mathrm{L}_{\mathrm{P}} /\left(\mathrm{E}^{2} \mathrm{~B}\right)_{\mathrm{P}}\right)$ by $[10]$. And hence As/s $\left.\in\left(\left(I A+E^{2} B\right)_{P}\right) /\left(E^{2} B\right)_{P}\right) \cap\left(L_{P} /\left(E^{2} B\right)_{P}\right)=$ $\left(\left(\mathrm{IA}+\mathrm{E}^{2} \mathrm{~B}\right) /\left(\mathrm{E}^{2} \mathrm{~B}\right)\right)_{\mathrm{P}} \cap\left(\mathrm{L} /\left(\mathrm{E}^{2} \mathrm{~B}\right)\right)_{\mathrm{P}}$ $\left(\left(\left(\mathrm{I}+\mathrm{E}^{2} \mathrm{~B}\right) /\left(\mathrm{E}^{2} \mathrm{~B}\right)\right) \cap\left(\mathrm{L} /\left(\mathrm{E}^{2} \mathrm{~B}\right)\right)\right)_{\mathrm{P}}$. Therefore $\mathrm{x} \in\left(\left(\mathrm{IA}+\mathrm{E}^{2} \mathrm{~B}\right) /\left(\mathrm{E}^{2} \mathrm{~B}\right)\right) \cap\left(\mathrm{L} /\left(\mathrm{E}^{2} \mathrm{~B}\right)\right)$ which implies $\mathrm{x} \in\left(\mathrm{I}\left(\mathrm{A} /\left(\mathrm{E}^{2} \mathrm{~B}\right)\right) \cap\left(\mathrm{L} /\left(\mathrm{E}^{2} \mathrm{~B}\right)\right)\right.$ and hence $\mathrm{I}\left(\mathrm{L} / \mathrm{E}^{2} \mathrm{~B}\right) \subseteq\left(\mathrm{I}\left(\mathrm{A} /\left(\mathrm{E}^{2} \mathrm{~B}\right)\right) \cap\left(\mathrm{L} /\left(\mathrm{E}^{2} \mathrm{~B}\right)\right)\right.$. Therefore $\mathrm{I}\left(\mathrm{L} / \mathrm{E}^{2} \mathrm{~B}\right)=\left(\mathrm{I}\left(\mathrm{A} /\left(\mathrm{E}^{2} \mathrm{~B}\right)\right) \cap\left(\mathrm{L} /\left(\mathrm{E}^{2} \mathrm{~B}\right)\right)\right.$. Thus $\mathrm{L}^{2} \mathrm{E}^{2} \mathrm{~B}$ is pure submodule of $\mathrm{A} / \mathrm{E}^{2} \mathrm{~B}$. This proves that $A / E^{2} B$ is regular and finally $B$ is an $S M$-submodule of $A$.

Conversely: -

Suppose that B is an SM-submodule of $A$. To prove $\mathrm{B}_{\mathrm{P}}$ is $\mathrm{SM}$-submodule of an $\mathrm{S}_{\mathrm{p}}$-module

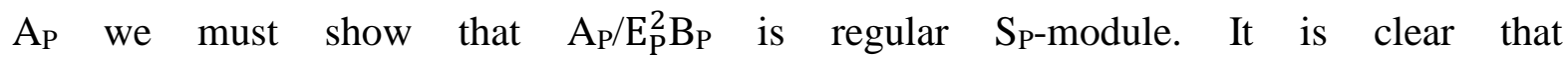
$\left(\mathrm{I}_{\mathrm{P}}\left(\mathrm{A}_{\mathrm{P}} / \mathrm{E}_{\mathrm{P}}^{2} \mathrm{~B}_{\mathrm{P}}\right)\right) \cap\left(\mathrm{L}_{\mathrm{P}} / \mathrm{E}_{\mathrm{P}}^{2} \mathrm{~B}_{\mathrm{P}}\right) \subseteq \mathrm{I}_{\mathrm{P}}\left(\mathrm{L}_{\mathrm{P}} / \mathrm{E}_{\mathrm{P}}^{2} \mathrm{~B}_{\mathrm{P}}\right)$. To prove $\mathrm{I}_{\mathrm{P}}\left(\mathrm{L}_{\mathrm{P}} / \mathrm{E}_{\mathrm{P}}^{2} \mathrm{~B}_{\mathrm{P}}\right) \subseteq\left(\mathrm{I}_{\mathrm{P}}\left(\mathrm{A}_{\mathrm{P}} / \mathrm{E}_{\mathrm{P}}^{2} \mathrm{~B}_{\mathrm{P}}\right)\right) \cap\left(\mathrm{L}_{\mathrm{P}} / \mathrm{E}_{\mathrm{P}}^{2} \mathrm{~B}_{\mathrm{P}}\right)$ . Let $\mathrm{x} / 1 \in \mathrm{I}$ and $\mathrm{a} / \mathrm{s} \in \mathrm{I}_{\mathrm{P}}\left(\mathrm{L}_{\mathrm{P}} / \mathrm{E}_{\mathrm{P}}^{2} \mathrm{~B}_{\mathrm{P}}\right)\left(\mathrm{xa} / \mathrm{s}+\mathrm{E}_{\mathrm{P}}^{2} \mathrm{~B}_{\mathrm{P}}\right)=\sum_{\mathrm{i}=0}^{\mathrm{n}}\left(\mathrm{b}_{\mathrm{i}} / \mathrm{s}_{\mathrm{i}}\right)\left(\mathrm{l}_{\mathrm{i}} / \mathrm{t}_{\mathrm{i}}+\mathrm{E}_{\mathrm{P}}^{2} \mathrm{~B}_{\mathrm{P}}^{2}\right)$ where $\mathrm{s}_{\mathrm{i}}, \mathrm{t}_{\mathrm{i}} \notin \mathrm{P}$ and $b_{i} \in I, l_{i} \in L$. Put $c_{i}=s_{i} t_{i}$. Therefore $\left(x a / s+E_{P}^{2} B_{P}\right)=\left(\left(b_{1} l_{1} v_{1}+b_{2} l_{2} v_{2}+\ldots+b_{n} l_{n} v_{n}\right) / u\right)+E_{P}^{2} B_{P}^{2}$ where $\mathrm{u}=\mathrm{c}_{1} \mathrm{c}_{2} \mathrm{c}_{3} \ldots . \mathrm{c}_{\mathrm{n}}$ and $\mathrm{v}_{1}=\mathrm{c}_{2} \mathrm{c}_{3} \ldots \mathrm{c}_{\mathrm{n}}, \mathrm{v}_{2}=\mathrm{c}_{1} \mathrm{c}_{3} \mathrm{c}_{4} \ldots . \mathrm{c}_{\mathrm{n}}, \mathrm{v}_{\mathrm{n}}=\mathrm{c}_{1} \mathrm{c}_{2} \mathrm{c}_{3} \ldots . \mathrm{c}_{\mathrm{n}-1}$. Thus there exist $\mathrm{k} \notin \mathrm{P}$ such that $\mathrm{kxau}+\mathrm{E}^{2} \mathrm{~B}=\mathrm{k}\left(\mathrm{b}_{1} \mathrm{l}_{1} \mathrm{v}_{1}+\mathrm{b}_{2} \mathrm{l}_{2} \mathrm{v}_{2}+\ldots+\mathrm{b}_{\mathrm{n}} \mathrm{l}_{\mathrm{n}} \mathrm{v}_{\mathrm{n}}\right) \in \mathrm{I}\left(\mathrm{L} / \mathrm{E}^{2} \mathrm{~B}\right)$ but $\mathrm{L}$ is pure submodule in $A$, that is $I\left(L / E^{2} B\right)=I\left(A / E^{2} B\right) \cap\left(L / E^{2} B\right)$ (Since $A / E^{2} B$ is regular S-module) and hence by (13,theorem (2.6)] we have $\left(x a+E^{2} B\right) \in I\left(A / E^{2} B \cap L / E^{2} B\right)$. This leads us to write $\quad\left(\mathrm{xa} / \mathrm{s}+\mathrm{E}_{\mathrm{P}}^{2} \mathrm{~B}_{\mathrm{P}}\right) \in\left(\mathrm{I}_{\mathrm{P}}\left(\mathrm{A}_{\mathrm{P}} / \mathrm{E}_{\mathrm{P}}^{2} \mathrm{~B}_{\mathrm{P}}\right) \cap\left(\mathrm{L}_{\mathrm{P}} / \mathrm{E}_{\mathrm{P}}^{2} \mathrm{~B}_{\mathrm{P}}\right)\right.$. This gives $\mathrm{I}_{\mathrm{P}}\left(\mathrm{L}_{\mathrm{P}} / \mathrm{E}_{\mathrm{P}}^{2} \mathrm{~B}_{\mathrm{P}}\right) \subseteq$ $\left(\mathrm{I}_{\mathrm{P}}\left(\mathrm{A}_{\mathrm{P}} / \mathrm{E}_{\mathrm{P}}^{2} \mathrm{~B}_{\mathrm{P}}\right)\right) \cap\left(\mathrm{L}_{\mathrm{P}} / \mathrm{E}_{\mathrm{P}}^{2} \mathrm{~B}_{\mathrm{P}}\right)$ and $\mathrm{A}_{\mathrm{P}} / \mathrm{E}_{\mathrm{P}}^{2} \mathrm{~B}_{\mathrm{P}}$ is a regular $\mathrm{S}_{\mathrm{P}}$-module and finally, we obtain that $B_{P}$ is an SM-submodule of $A_{P}$.

\section{Proposition (4.3):}

Let $\mathrm{L}, \mathrm{B}$ be two finitely generated submodules of an S-module A. If $\mathrm{L}_{\mathrm{P}}, \mathrm{B}_{\mathrm{P}}$ are SMsubmodules of $\mathrm{A}_{\mathrm{P}}$, then $\mathrm{L} \cap \mathrm{B}$ is an SM-submodule of $\mathrm{A}$.

\section{Proof:}

Since L, B are two finitely generated submodules of A, then by $\{10, \mathrm{p} 24\},\left[\mathrm{LP}_{\mathrm{P}}: \mathrm{B}_{\mathrm{P}}\right]+$ $\left[B_{P}: L_{P}\right]=S_{P}$ for every maximal ideals $P$ of $S$. Thus, $L_{P} \cap B_{P}=L_{P}$ or $L_{P} \cap B_{P}=B_{P}$, but $L_{P}$ and $B_{P}$ are $S M$-submodules, then $L_{P} \cap B_{P}$ is an SM-submodule, and we have $L_{P} \cap B_{P}=(L \cap B)_{P}$. Therefore $(\mathrm{L} \cap \mathrm{B})_{\mathrm{P}}$ is an SM-submodule and by proposition(4.2), $\mathrm{L} \cap \mathrm{B}$ is an SM-submodule of $\mathrm{A}$.

\section{Proposition (4.4):}

Let $\mathrm{L}, \mathrm{B}$ be two finitely generated submodules of an S-module A. Then, $\mathrm{L}+\mathrm{B}$ is an SMsubmodules of $\mathrm{A}$, if $\mathrm{L}_{\mathrm{P}}, \mathrm{B}_{\mathrm{P}}$ are $\mathrm{SM}$-submodules of an $\mathrm{S}_{\mathrm{P}}$-module $\mathrm{A}_{\mathrm{P}}$. 


\section{Proof:}

Let L, B be two finitely generated submodules of $\mathrm{A}$. Then by $\{10, \mathrm{p} 24\}$, we have $\left[L_{P}: B_{P}\right]+\left[B_{P}: L_{P}\right]=S_{P}$ for every maximal ideal $P$ of $S$. Let $y_{1} \in\left[L_{P}: B_{P}\right]$ and $y_{2} \in\left[B_{P}: L_{P}\right]$ such that $\mathrm{y}_{1}+\mathrm{y}_{2}=1=$ unity of $S_{P}$. Then, either $\mathrm{y}_{1}$ is a unit element or $\mathrm{y}_{2}$ is a unit element (Since $\mathrm{S}_{\mathrm{P}}$ is local ring). Therefore $\left[L_{P}: B_{P}\right]=S_{P}$ or $\left[B_{P}: L_{P}\right]=S_{P}$ and hence either $L_{P} \subseteq B_{P}$ or $B_{P} \subseteq L_{P}$ which implies $L_{P}+B_{P}=L_{P}$ or $L_{P}+B_{P}=B_{P}$, but $L_{P}, B_{P}$ are $S M$-submodules of $A_{P}$. Thus $L_{P}$ $+\mathrm{B}_{\mathrm{P}}$ is an $\mathrm{SM}$-submodule and $(\mathrm{L}+\mathrm{B})_{\mathrm{P}}$ is an $\mathrm{SM}$-submodule and by proposition(4.2), $\mathrm{L}+\mathrm{B}$ is an SM-submodule of A.

\section{Conclusion}

The conclusion of this work is to study an important concept, namely strongly maximal submodule. Some properties and many results were proved and the behavior of that concept with its localization were studied and shown.

\section{References}

1. Burton, D. M. 1970. A first course in rings and ideals. Addison-Wesley.

2. Sahera Mahmod Yasin About regular module type-F, Master letter,Scince College,Univ.of Baghdad, 1993.

3. Khalaf, H.Y. Semimaximal Submodules Ph.D.Thesis, Univ. of Baghdad, 2007.

4. Frank W. , Anderson K. and . Fuller R., Rings and Categories of Modules, SpringerVerlag, Berlin, Heidelberg , New York, 1974.

5. Lu.C.P., M-Radicals of Submodules in Modules, Math. Japon., 34 1989, 211-219.

6. Kazem, A.D. Some Types of Visible Submodules and Fully visible Modules M.sc.Thesis, Univ. of Baghdad,2020 .

7. Goldie, K.R. Torsion Free Modules and Rings,J.Algebra,1,268-287, 1964.

8. Larson M.D., Mc Carthy P.J., 1971, Multiplication theory of Ideals, Academic press, New York and London.

9. Fieldhouse, D.J. Pure Theories, Math.Ann., 184,1-18,1969.

10. Mijbass A.S., On Cancelation modules, M.Sc. Thesis, Baghdad university, 1992.

11. Faris, H. I., Jasim, R. H., \& Mohammed, N. J. 2021, March. Pseudo maximal submodules. In Journal of Physics: Conference Series (Vol. 1818, No. 1, p. 012055). IOP Publishing.

12. Mohammed, A. S., \& Sallman, M. D. 2017. 2-Maximal Submodules and Related Concepts. Journal of university of Anbar for Pure science, 11(3).

13. Jud H.M. , Some types of fully cancelation modules , M.sc.Thesis, Baghdad University,2016. 